\title{
Biosynthesis of Proparathyroid Hormone and Parathyroid Hormone by Human Parathyroid Glands
}

\author{
Luke L. H. Chu, Ronal R. MacGregor, Paul I. Liv, \\ James W. Hamilton, and David V. CohN \\ From the Calcium Research Laboratory, Veterans Administration Hospital, \\ Kansas City, Missouri 64128; University of Missouri-Kansas City, School of \\ Dentistry, Kansas City, Missouri 64108; and University of Kansas, School of \\ Medicine, Kansas City, Kansas 66103
}

\begin{abstract}
A в S T R A C T Human parathyroid glands obtained at autopsy were incubated with $\left[{ }^{3} \mathrm{H}\right]$ leucine and $\left[{ }^{3} \mathrm{H}\right]$ lysine. After incubation, nonradioactive parathyroid tissue of either human or bovine origin was added. Radioactive parathyroid hormone and proparathyroid hormone were isolated from the gland and medium by organic solvent and salt fractionation, trichloroacetic acid precipitation, Sephadex G-100 gel filtration, and carboxymethyl cellulose column chromatography. The human hormonal peptides were identified in the ion-exchange column eluates by their relatively high levels of radioactivity, their elution positions, and their immunoreactivity to antiPTH antiserum. The time-course of radioactive amino acid incorporation into these peptides and a brief incubation of the gland with radioactive amino acids, followed by various lengths of incubation with nonradioactive amino acids, indicated that a precursor-product relationship exists for the two peptides. An alternate method for isolation of the hormone and prohormone, which involves separation of peptides by urea-polyacrylamide gel electrophoresis, confirmed the identities of the human parathyroid hormone and proparathyroid hormone.
\end{abstract}

\section{INTRODUCTION}

Studies of bovine parathyroid glands indicate that parathyroid hormone $(\mathrm{PTH})^{1}$ is synthesized from a larger precursor designated as proparathyroid hormone (Pro-

Received for publication 22 May 1973 and in revised form 1 August 1973.

${ }_{1}$ Abbreviations used in this paper: CM, carboxymethyl; GP-6, guinea pig anti-bovine PTH antiserum; ProPTH, proparathyroid hormone; $\mathrm{PTH}$, parathyroid hormone; SDS, sodium dodecyl sulfate; TCA, trichloroacetic acid.
PTH ${ }^{2}$ (1-4). The bovine prohormone has a molecular weight of about 12,000 , compared to 9,600 for the hormone, and contains about 20 more amino acid residues than does PTH (4). The amino acid sequence corresponding to the first 40 residues of bovine ProPTH has been determined. The molecule consists of the hexapeptide Lys-Ser-Val-Lys-Lys-Arg at the amino-terminal end followed by a sequence corresponding to residues 1-34 of PTH (5). These data suggest that the prohormone consists of the PTH molecule as the central portion with the hexapeptide at the amino-terminal end and perhaps an additional 14 residues at the carboxyl-terminal end. In contrast to this interpretation, Habener, Kemper, Potts, and Rich (6) presented evidence that the carboxyl-terminal end of ProPTH and PTH are the same. A definitive description of the entire sequence of the molecule requires further analysis.

Recent structural analysis of ProPTH also indicates that more than one species of prohormone may exist (5). Some of the individual species could represent cleavage products in situ or during isolation procedures. It is possible therefore that there might exist a yet larger prohormone containing even more additional amino acid residues than does the present ProPTH.

In addition to the presence of the prohormone in the bovine parathyroid gland, ProPTH exists in parathyroid glands of chicken (7) and rat (8), and its synthesis has recently been documented in human parathyroid adenoma $(4,9,10)$. These findings suggest that the prohormone-hormone pathway for the formation of $\mathrm{PTH}$ in the parathyroid gland is common in all higher animals.

\footnotetext{
2The term "ProPTH" as used in this paper is synonymous with "calcemic Fraction-A," the name originally applied by us to this substance $(1,2)$.
} 


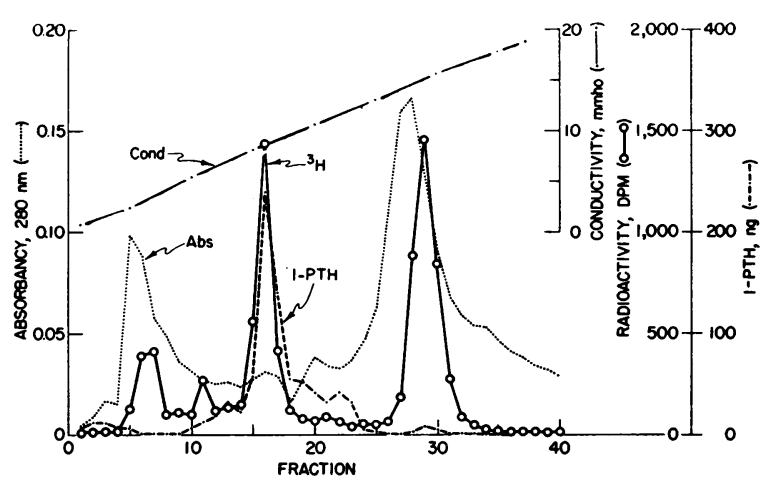

Figure 1 CM cellulose chromatography of human parathyroid TCA powder. The TCA powder was prepared from $10 \mathrm{mg}$ of incubated $(3 \mathrm{~h})$ and $2 \mathrm{~g}$ of frozen human parathyroid gland tissue. This preparation was dissolved in $0.01 \mathrm{M}$ ammonium acetate, $\mathrm{pH} 5.3$, and applied to a $\mathrm{CM}$ cellulose column $(7 \times 80 \mathrm{~mm})$ equilibrated with the same buffer. The column was eluted with a linear ammonium acetate gradient (total vol $120 \mathrm{ml}$ ) from $0.01 \mathrm{M}$, $\mathrm{pH} 5.3$, to $0.30 \mathrm{M}, \mathrm{pH} 7.0$. Each fraction contained $3.0 \mathrm{ml}$ Portions of $0.1 \mathrm{ml}$ were assayed. Immunoreactivity is expressed as immunoreactivity PTH equivalents (I-PTH) per aliquot. Radioactivity is shown as dpm per portion.

Currently there is considerable interest in certain circulating peptide fractions related to glandular PTH. These molecules, none of which have been isolated, are reported to be smaller than PTH (11-14). At least one of these fractions appears to be biologically active (15). From radioimmunoassay with a variety of antisera, it appears that a major fraction of these peptides consists of fragments of $\mathrm{PTH}$ that contain the carboxyl-terminal end of the hormone (14). Although it is clear that one route of formation of these peptides is via cleavage of PTH after its secretion (12), it is not ruled out that in addition some molecular species might be directly released from the gland. Furthermore, should ProPTH be secreted in addition to PTH, it is possible that some of the circulating peptides might be derived from the prohormone.

Consequently, it is of importance to determine the steps of formation of $\mathrm{PTH}$ in the normal human gland, to characterize those glandular peptide molecules related to the hormone, and ultimately to relate these if possible to the circulating species. The present report demonstrates that human postmortem parathyroid glands can incorporate radioactive amino acids into $\mathrm{PTH}$ and indicates that the hormone is formed from ProPTH as it is in parathyroid glands of other species.

\section{METHODS}

Human parathyroid glands were obtained at autopsy from 55 men over a period of $6 \mathrm{mo}$. In general, the tissue was dissected within $10 \mathrm{~h}$ after death and was stored frozen. These patients died from a variety of causes unrelated to parathyroid disease and did not have hypercalcemia.
The glands for the short-term incubation studies were obtained from four subjects within $3 \mathrm{~h}$ after death and were immediately transferred to the laboratory. These four patients ranged in age from 46 to $83 \mathrm{yr}$; two died of liver cirrhosis; one, of lung cancer; and one, of intestinal obstruction. Before death the levels of serum calcium and inorganic phosphate of these patients were all within normal limits. None of the cases had signs or symptoms of hyper-or hypoparathyroidism.

In each incubation study, two glands (about $50 \mathrm{mg}$ total wt) from the same subject were trimmed of fat and connective tissue, cut into small pieces, and incubated at $37^{\circ} \mathrm{C}$ in $0.5 \mathrm{ml}$ of Tris-containing buffer containing 10 $\mathrm{mM}$ glucose and $1.25 \mathrm{mM} \mathrm{CaCl}$ (8). $30 \mathrm{~min}$ later, the tissues were transferred to $0.5 \mathrm{ml}$ of the fresh buffer containing $25 \mu \mathrm{Ci}$ each of $\left[{ }^{3} \mathrm{H}\right]$ lysine and $\left[{ }^{3} \mathrm{H}\right]$ leucine. At the end of various periods of incubation, $4.5 \mathrm{ml}$ of icecold $8 \mathrm{M}$ urea- $0.2 \mathrm{M} \mathrm{HCl}$ containing $0.1 \mathrm{M}$ cysteine and $10 \mathrm{mM}$ each of nonradioactive leucine and lysine were added to terminate the reaction, and the mixture (gland and medium) was homogenized. In one of these experiments, the batch of nonradioactive human parathyroid tissue stored frozen (approximately $2 \mathrm{~g}$ in weight) was similarly homogenized and added to the homogenate of the incubated fresh tissue. In the remainder of the experiments, a homogenate of $4 \mathrm{~g}$ of nonradioactive bovine parathyroid glands was added to each fresh human tissue homogenate to increase the amount of tissue protein in order to minimize losses of material in the subsequent purification procedure (16).

Unless stated otherwise, the trichloroacetic acid (TCA) powder method ${ }^{3}$ for isolating PTH and ProPTH was followed $(2,16)$. This procedure includes organic solvent and salt fractionation and TCA precipitation to yield a preparation called TCA powder, followed usually by Sephadex G-100 gel filtration and carboxymethyl (CM) cellulose column chromatography. Under these conditions, the recovery of radioactivity was $65 \%$ from Sephadex columns and $60 \%$ from $\mathrm{CM}$ cellulose columns. The recovery from CM cellulose columns could be increased to $90-95 \%$ by inclusion of $8 \mathrm{M}$ urea in the elution gradients, but the ratio of the two major peaks (PTH and ProPTH) remained constant. When indicated, the gel filtration step was deleted, and the TCA powder was applied directly to the ion-exchange column.

In order to compare the hormone and prohormone fractions obtained by the TCA-powder method and those by the urea- $\mathrm{HCl}$-extract method, fresh gland slices were extracted with $8 \mathrm{M}$ urea-0.2 $\mathrm{M}$ HCl-0.1 $\mathrm{M}$ cysteine as described (3). The proteins in the extract were twice precipitated and resuspended with $10 \%$ TCA and $0.1 \mathrm{~N}$ $\mathrm{NaOH}$, respectively. They were precipitated again as above, resuspended in $\mathrm{H}_{2} \mathrm{O}$, and lyophilized. The resultant dry powder was extracted with $8 \mathrm{M}$ urea-0.1 M acetic acid. Samples of the final extract were subjected to electrophoresis both on polyacrylamide gels at $\mathrm{pH} 4.4$ containing $10 \%$ acrylamide, $0.25 \%$ bisacrylamide, and $8 \mathrm{M}$ urea, and on polyacrylamide gels at $\mathrm{pH} 7.4$ containing $10 \%$ acrylamide, $1.5 \%$ bisacrylamide, $0.1 \%$ sodium dodecyl sulfate (SDS), and $8 \mathrm{M}$ urea, as described (3). Under these conditions the radioactivity recovered in the region of ProPTH/PTH was about $30 \%$ of that applied to the gel.

${ }^{3}$ For simplicity we will use the term TCA powder method to refer to the original procedure $(2,16)$ and the term urea-HCl extract method to refer to the alternate procedure introduced hy Kemper, Habener, Potts, and Rich (3). 
Radioimmunoassay was performed as described earlier (16), employing guinea pig anti-bovine PTH antiserum (GP-6) at a final dilution of $1: 100,000 .{ }^{125}$ I-labeled bovine $\mathrm{PTH}$ was used as tracer. Homogeneous bovine PTH prepared in this laboratory (16) was used to construct the standard curve. Human PTH (derived from the batch preparation described above) and the homogeneous bovine $\mathrm{PTH}$ yielded parallel curves in this assay.

$\left[{ }^{3} \mathrm{H}\right]$ leucine and $\left[{ }^{3} \mathrm{H}\right]$ lysine (both $25 \mathrm{Ci} / \mathrm{mmol}$ ) were purchased from New England Nuclear, Boston, Mass. Materials used in polyacrylamide gel electrophoresis were obtained from Canalco, Inc., Rockville, Md. All other conventional chemicals were of analytical grade and were obtained from Fisher Chemical Co., St. Louis, Mo. Bovine parathyroid glands were provided by Wilson Packing Company, Kansas City, Mo., and Dugdale Packing Co., St. Joseph, Mo.

\section{RESULTS}

Figs. 1-3 provide evidence that human parathyroid glands obtained at autopsy contain and are able to synthesize PTH and ProPTH.

The results of processing the $2-\mathrm{g}$ batch of human radioactive and nonradioactive parathyroid glands through the $\mathrm{CM}$ cellulose chromatographic step are shown in Fig. 1. Two major bands of radioactivity (fractions 1517; fractions 27-31), presumably representing human hormone and prohormone, respectively, were eluted at conductivities similar to those of bovine and rat $\mathrm{PTH}$ and ProPTH $(2,8)$. Fraction by fraction analysis indicated that a major (fraction 16) and a minor (fraction 29) peak of immunoreactivity coincided with the two major radioactivity peaks. These two immunoreactive peaks, when examined in a separate assay, yielded an identical assay curve (bound $\left[{ }^{125} \mathrm{I}\right] \mathrm{PTH} /$ free $\left[{ }^{125} \mathrm{I}\right] \mathrm{PTH}$ vs. amount of sample). The ratio of the total immunoreactivity under these two peaks was estimated to be $27: 1$ (PTH:ProPTH). A few radioactive peaks (fractions $5-8,10-12$ ) and immunoreactive peaks (fractions 2-4, 11-14, 18-20, 21-23) were also observed in Fig. 1. The radioactive peaks might represent as yet unrecognized, rapidly-turning-over molecules related to $\mathrm{PTH}$ or Pro$\mathrm{PTH}$, or they might represent some unrelated impurities at the TCA powder step of the purification. The immunoreactive peaks, though prominent, were not associated with any of the radioactive peaks. It is therefore not likely that they represent breakdown products of the newly synthesized ProPTH or PTH. On the other hand, these fractions could represent some breakdown products of preexisting and hence nonradioactive $\mathrm{PTH}$ in the parathyroid glands. The chemical nature of these radioactive and immunoreactive fractions are currently undergoing analysis and will not be described further in the present report. The protein elution pattern was complex. A small absorbancy peak corresponded to the radioactivity and immunoreactivity peak and presumably consisted of PTH protein. A major late-eluting absorbancy

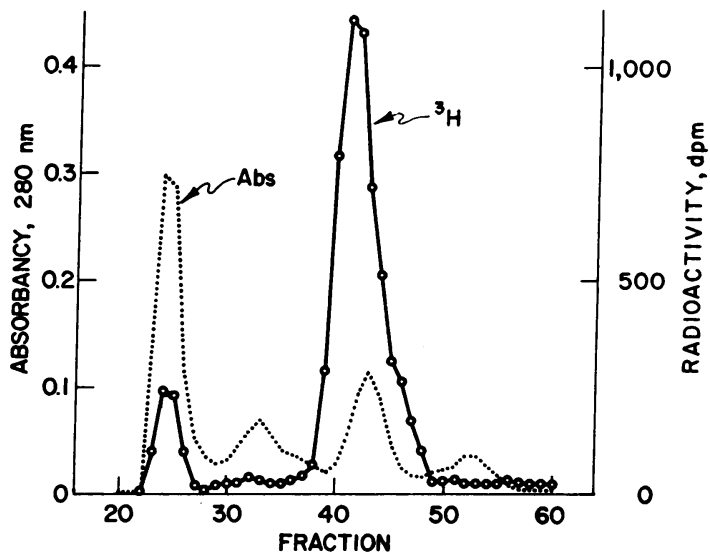

Figure 2 Gel filtration of mixed human and bovine parathyroid TCA powder. The TCA powder was prepared from $30 \mathrm{mg}$ of human parathyroid gland incubated $3 \mathrm{~h}$ and $4 \mathrm{~g}$ of frozen bovine parathyroid tissue. The preparation was dissolved in $6 \mathrm{ml}$ of $0.14 \mathrm{M}$ ammonium acetate, $\mathrm{pH}$ 4.8 buffer, and filtered through a $2.5 \times 40-\mathrm{cm}$ column of G-100 Sephadex (superfine). The same buffer was used to elute the column. Fractions of $2.7 \mathrm{ml}$ were collected, and portions of $0.5 \mathrm{ml}$ were assayed. Data are expressed as $\mathrm{dpm}$ per portion. Void volume $=62 \mathrm{ml}$ (Fraction 23). Inner volume $=160 \mathrm{ml}($ Fraction 60$)$.

peak (Fractions 24-31) that encompassed the radioactive ProPTH peak was also observed. It coincided with neither the radioactive nor the immunoreactive ProPTH peak. Thus the great majority of this band could not represent ProPTH protein.

When radioactive human gland homogenates were mixed with the homogenate of nonradioactive bovine tissue carrier and processed by the TCA powder method to the gel filtration stage, a profile typical of that shown in Fig. 2 was obtained. It should be emphasized that in this type of study the radioactivity is exclusively derived from the human tissue, whereas the protein is essentially that of the bovine carrier. A major band of radioactivity with a peak at fraction 41 preceded the bovine $\mathrm{PTH}$ protein peak (fraction 43) (2). Further processing of the material comprising this radioactive peak by CM cellulose chromatography yielded the elution profile shown in Fig. 3. The human PTH (fractions 22-26) preceded the bovine PTH (Fractions 24-27). The radioactive ProPTH (fractions 41-46) was not associated with a discernible protein band. An early-eluting peak (fraction 13) seemed to be equivalent to a similar peak detected in the experiment portrayed in Fig. 1. In a separate experiment (not shown) in the presence of $8 \mathrm{M}$ urea, a qualitatively similar pattern was obtained in which the same three major radioactive peaks shown in Fig. 3 were eluted. Human PTH again was eluted slightly earlier than the bovine PTH.

The presence of the human radioactive prohormone in parathyroid glands was also confirmed by the method of 
Kemper et al. (3). Fig. 4 portrays urea-polyacrylamide gel patterns of the radioactive extracts obtained from radioactive human parathyroid tissue by the urea- $\mathrm{HCl}$ extract method. On the gel that did not contain SDS (Fig. 4A) a major band of radioactivity migrated more rapidly than did the immunoreactive $\mathrm{PTH}$. On the gel containing SDS (Fig. 4B) the major radioactive peak migrated more slowly than did the immunoreactive $\mathrm{PTH}$. These patterns correspond closely to those shown by Habener, Kemper, Potts, and Rich (9) for PTH and ProPTH obtained from parathyroid adenoma.

In order to ascertain that the major radioactive band developed on each gel was equivalent to the ProPTH isolated from CM cellulose chromatography by TCA powder method, the following experiment was performed. Portions of the gel containing the immunoreactive and radioactive bands were extracted with acetic acid. These extracts were pooled, mixed with bovine parathyroid TCA powder, and subjected to CM cellulose chromatography. The elution pattern for the extract from the gel that did not contain SDS is shown in Fig. 5. (That for the extract from the SDS-containing gel was essentially the same and is not illustrated.) The major radioactive peak (fractions 32-36) corresponded to ProPTH. A smaller peak (fractions 15-19), eluted earlier than the bovine PTH protein peak (fractions $17-$ 20 ), corresponded to human PTH. Also noted in the elution profile were several minor unidentified radioactive peaks that accounted for more than one-third of the recovered radioactivity.

Fig. 6 shows the kinetics of synthesis of ProPTH and $\mathrm{PTH}$. The incorporation of radioactivity into ProPTH began promptly. PTH synthesis, in contrast, lagged initially and then accelerated (Fig. 6A). When a 30-min

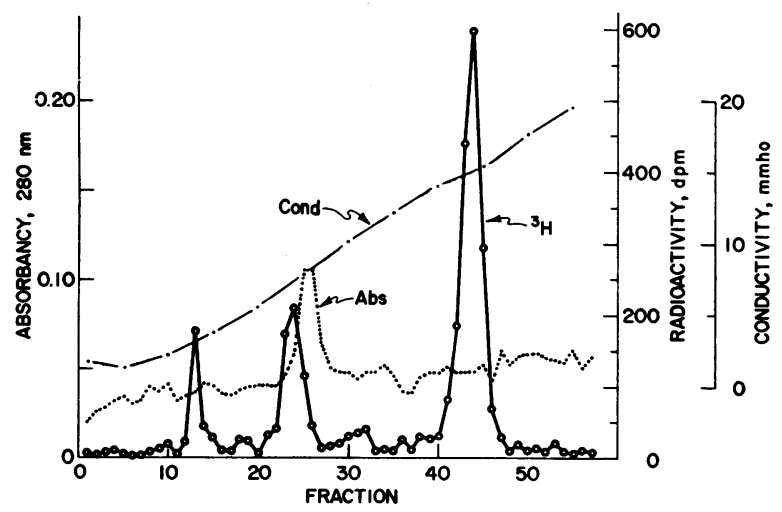

Figure 3 CM cellulose chromatography of gel filtration fractions. Fractions 39-47 from the Sephadex column of Fig. 2 were combined and lyophilized. The dry powder was dissolved in $0.01 \mathrm{M}, \mathrm{pH} 5.3$, ammonium acetate buffer and chromatographed on a $7 \times 80-\mathrm{mm} \mathrm{CM}$ cellulose column as described in the legend of Fig. 1. Each fraction contained $3.0 \mathrm{ml}$ and portions of $0.5 \mathrm{ml}$ were assayed.

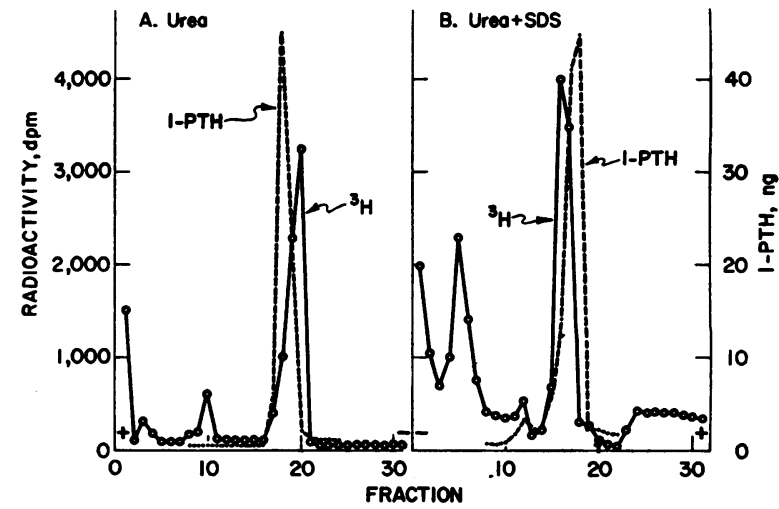

Figure 4 Polyacrylamide gel electrophoresis of human parathyroid gland extracts. $30 \mathrm{mg}$ of freshly incubated human tissue was processed by the urea- $\mathrm{HCl}$ extract method. A. One half of the final $8 \mathrm{M}$ urea- $0.1 \mathrm{M}$ acetic acid extract was analyzed by-electrophoresis on ureapolyacrylamide gel at $\mathrm{pH} 4.4 ; \mathrm{B}$. the other half of the extract was neutralized with $\mathrm{NaOH}$ and analyzed by electrophoresis on SDS-urea polyacrylamide gel at $\mathrm{pH} 7.2$. After electrophoresis, each was cut transversely into 1.5$\mathrm{mm}$ slices. One half of each slice was dissolved in $\mathrm{H}_{2} \mathrm{O}_{2}$ and assayed for radioactivity. The remaining halves were extracted at $4^{\circ} \mathrm{C}$ overnight with $0.5 \mathrm{ml}$ of $0.1 \mathrm{M}$ acetic acid. Portions of $0.1 \mathrm{ml}$ of the extracts were subjected to radioimmunoassay. The data are expressed as immunoreactive PTH equivalents (I-PTH) per portion.

incubation with $\left[{ }^{3} \mathrm{H}\right]$ amino acids (pulse period) was followed by incubations with nonradioactive amino acids (chase period), the amount of radioactive ProPTH rapidly decreased (Fig. $6 \mathrm{~B}$ ). The radioactive $\mathrm{PTH}$, on the other hand, increased for an additional $30 \mathrm{~min}$ and then decreased. These patterns of incorporation and discharge of radioactivity were similar to those previously noted for the synthesis of prohormone and hormone in bovine and rat tissues $(4,8)$, and support the concept of a precursor-product relationship for the two peptides in human parathyroid glands.

\section{DISCUSSION}

Within a few hours after death, human parathyroid glands were still functional in terms of their ability to incorporate amino acids into $\mathrm{PTH}$ and ProPTH in an in vitro system. The hormone and prohormone were identified in the CM cellulose eluates and in polyacrylamide gel electrophoretograms by their relatively high levels of radioactivity, their elution or migratory positions, and their immunoreactivity. The time-course of incorporation of radioactivity and the pulse-chase data are in accord with a precursor-product relationship for the two molecules. These data, together with the similar results obtained from glands of other species, strengthen the conclusion that the formation of PTH from ProPTH represents a general pathway for PTH synthesis in higher animals $(4,7-10)$. 
The finding of only a small peak of immunoreactivity corresponding to the ProPTH (Fig. 1) in the human gland is similar to that reported for the bovine gland and could be explained for the same reasons: a smaller amount of prohormone than PTH in the tissue and a smaller degree of reactivity of the prohormone to the antiserum (4). Whether, in fact, human ProPTH and PTH differ in their reactivity to antiserum GP-6 can not be determined at this time, since neither peptide was sufficiently purified in the present study to allow such a comparison.

In the present study, ratios of radioactive ProPTH to PTH varied from $3: 1$ to $1: 1$. These values are in the range reported for human adenomatous tissues (9), and normal bovine (4) and rat parathyroid glands (8). We have shown previously that this ratio is affected by several factors. For example, a low dietary calcium intake appears to increase both the pool size of ProPTH in the glands and the proportion of ProPTH molecules converted to $\mathrm{PTH}$ (8). Both of these parameters affect the observed radioactive $\mathrm{ProPTH} / \mathrm{PTH}$ ratio. Moreover, because ProPTH/PTH ratio continuously decreases during the radioactive incubation period, (Fig. 6A), fortuitous changes in synthetic or degradation rate could markedly affect the radioactivity recovered in the hormone and prohormone. Therefore the physiological significance of differences in this ratio in the glandular tissue from one subject to another cannot be assessed without further study.

We observed that during cochromatography on ionexchange columns, PTH from human glands was always eluted earlier than the bovine hormone (Fig. 3 and 6). Yet it was reported that the migratory position in poly-

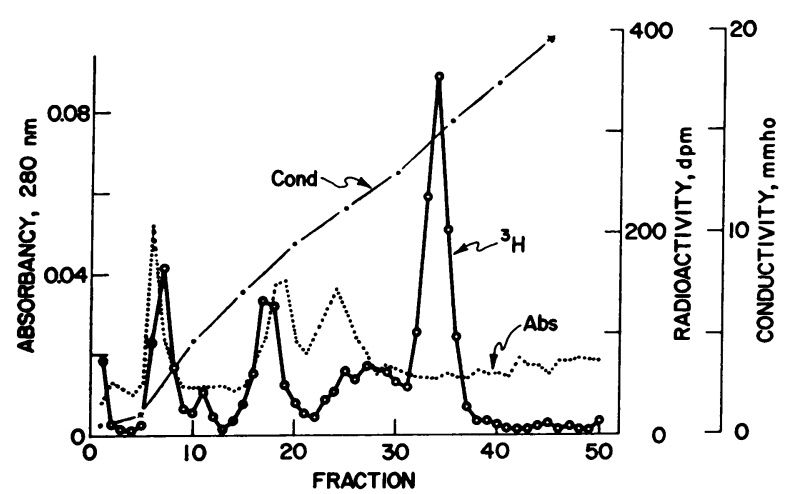

FIGURE $5 \mathrm{CM}$ cellulose chromatography of polyacrylamide gel bands. Aliquots of the $0.1 \mathrm{M}$ acetic acid extract of slices 17-21 (Fig. 5A) were combined, adjusted to $\mathrm{pH} 5.0$ with $\mathrm{NH}_{4} \mathrm{OH}$, and diluted with $\mathrm{H}_{2} \mathrm{O}$ to yield a conductivity of approximately 1 mmho. Bovine TCA powder prepared from $4 \mathrm{~g}$ of parathyroid tissue was mixed with this solution and applied to a CM cellulose column as described in the legend of Fig. 1. Portions of $1.0 \mathrm{ml}$ were assayed for radioactivity. Data are expressed as dpm per portion.

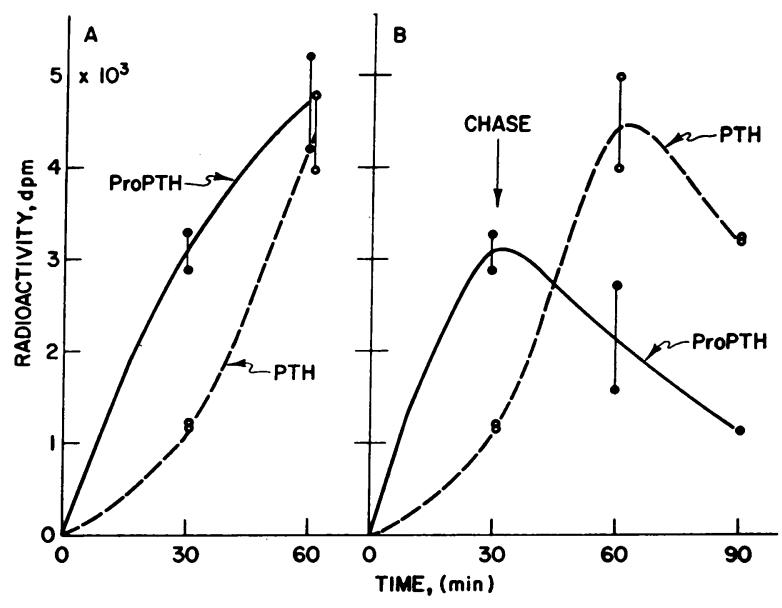

Figure 6 Kinetics of incorporation of radioactive amino acids into human PTH and ProPTH. A pair of human parathyroid glands (approximately $50 \mathrm{mg}$ ) was trimmed and cut into small pieces. These pieces were divided approximately evenly into 16 groups. Each group was incubated as described under Methods. A. At the designated times, the incubations were terminated by addition of cold urea- $\mathrm{HCl}$ containing $10 \mathrm{mM}$ each leucine and lysine. B. At the time indicated by the arrow labeled "chase," the tissues were transferred after rinsing to nonradioactive medium and incubation was continued as indicated. The tissues were homogenized, mixed with bovine carrier homogenate, and processed by the TCA powder method. In these studies the Sephadex G-100 step was deleted. The TCA powder was applied directly to CM cellulose columns to isolate PTH and ProPTH. Data are expressed as total dpm per peptide specimen.

acrylamide gels $(9,10,17)$ and elution position in CM cellulose chromatography (10) for PTH from human parathyroid adenomas were identical to those for bovine PTH. These apparent differences could imply that human PTH obtained from normal and from adenomatous tissues are different. However, a close examination of the chromatographic elution profile published by Martin, Greenberg, and Michelangeli (10) indicates that radioactive $\mathrm{PTH}$ from human adenoma cells was actually eluted somewhat earlier than the marker bovine PTH. Such data would support the notion that human PTH isolated from normal glands is chemically identical to that isolated from parathyroid adenomas.

The earlier-eluting character of human PTH compared to bovine PTH upon ion-exchange chromatography in the presence or absence of $8 \mathrm{M}$ urea implies that the human hormone is slightly less basic in ionic character than its bovine counterpart. Since the partial amino acid sequence (residues 1-34) of human PTH has been elucidated recently $(17,18)$ and shown to be more basic than or equally basic to the counter-portion in the bovine hormone, the present data predict, therefore, that the remaining portion of human PTH (residues 35-84) must be significantly less basic in ionic character than 
the counter-portion in bovine $\mathrm{PTH}$. In addition to the comparison of $\mathrm{PTH}$ molecules, the possibility of differences in ProPTH molecules remains to be studied.

It was not determined in the present study whether or not ProPTH was released into the medium during the incubation of parathyroid gland slices. If such were the case, it is possible that ProPTH might similarly be secreted from the gland in situ. Such an event would contribute to the pool of PTH-related peptides detected in the blood (11-14). Moreover, the immunoactive substances that were detected in glandular extracts (e.g., Fig. 1) might represent some turnover products of the hormone or prohormone and might exist in the gland in vivo. These species, too, might be released by the gland, and could further contribute to the complexity of the circulating hormonal peptides. It is apparent that further studies involving chemical comparisons are required in order to clarify the potential relationships between the glandular and circulating species.

\section{ACKNOWLEDGMENTS}

We wish to acknowledge Mrs. Carol Flowers for her excellent technical assistance.

This work was supported in part by grant DE 1523 from the National Institute of Dental Research and grant AM 15951 from the National Institute of Arthritis and Metabolic Diseases.

\section{REFERENCES}

1. Cohn, D. V., R. R. MacGregor, L. L. H. Chu, and J. W. Hamilton. 1972. Studies on the biosynthesis in vitro of parathyroid hormone and other calcemic polypeptides of the parathyroid gland. In Calcium, Parathyroid Hormone, and the Calcitonins. R. V. Talmage and P. L. Munson, editors. Excerpta Medica Foundation, Publishers, Amsterdam. 173.

2. Hamilton, J. W., R. R. MacGregor, L. L. H. Chu, and D. V. Cohn. 1971. The isolation and partial purification of a non-parathyroid hormone calcemic fraction from bovine parathyroid glands. Endocrinology. 89: 1440.

3. Kemper, B., J. F. Habener, J. T. Potts, Jr., and A. Rich. 1972. Proparathyroid hormone: identification of a biosynthetic precursor to parathyroid hormone. Proc. Natl. Acad. Sci. U. S. A. 69: 643.

4. Cohn, D. V., R. R. MacGregor, L. L. H. Chu, J. R. Kimmel, and J. W. Hamilton. 1972. Calcemic fractionA : biosynthetic peptide precursor of parathyroid hormone. Proc. Natl. Acad. Sci. U. S. A. 69: 1521.

5. Hamilton, J. W., H. D. Niall, H. T. Keutmann, J. T. Potts, Jr., and D. V. Cohn. 1973. Amino terminal se- quence of bovine proparathyroid hormone (calcemic fraction A). Fed. Proc. 32: 269. (Abstr.)

6. Habener, J. F., B. Kemper, J. T. Potts, Jr., and A. Rich. 1973. Bovine proparathyroid hormone: structural analysis of radioactive peptides formed by limited cleavage. Endocrinology. $92: 219$.

7. MacGregor, R. R., L. L. H. Chu, J. W. Hamilton, and D. V. Cohn. 1973. Partial purification of parathyroid hormone from chicken parathyroid glands. Endocrinology. $92: 1312$.

8. Chu, L. L. H., R. R. MacGregor, C. S. Anast, J. W. Hamilton, and D. V. Cohn. 1973. Studies on the biosynthesis of rat parathyroid hormone and proparathyroid hormone: adaptation of the parathyroid gland to dietary restriction of calcium. Endocrinology. In press.

9. Habener, J. F., B. Kemper, J. T. Potts, Jr., and A. Rich. 1972. Proparathyroid hormone: biosynthesis by human parathyroid adenomas. Science (Wash. D. C.). $178: 630$

10. Martin, R. J., P. B. Greenberg, and V. Michelangeli. 1972. Synthesis of human parathyroid hormone by cultured cells: evidence for release of prohormone by some adenomata. Clin. Sci. (Oxf.). 44: 1.

11. Arnaud, C. D., G. W. Sizemore, S. B. Oldham, J. A. Fischer, H. S. Tsao, and E. T. Littledike. 1971. Human parathyroid hormone: glandular and secreted molecular species. Am. J. Med. 50: 630.

12. Habener, J. F., D. Powell, T. M. Murray, G. P. Mayer, and J. T. Potts, Jr. 1971. Parathyroid hormone: secretion and metabolism in vivo. Proc. Natl. Acad. Sci. U.S. A. 68: 2986.

13. Canterbury, J. M., and E. Reiss. 1971. Multiple immunoreactive molecular forms of parathyroid hormone in human serum. Proc. Soc. Exp. Biol. Med. 140: 1393.

14. Segre, G. V., J. F. Habener, D. Powell, G. W. Tregear, and J. T. Potts, Jr. 1972. Parathyroid hormone in human plasma. Immunochemical characterization and biological implications. J. Clin. Invest. 51: 3163.

15. Canterbury, J. M., G. S. Levey, and E. Reiss. 1973. Activation of renal cortical adenylate cyclase by circulating immunoreactive parathyroid hormone fragments. J. Clin. Invest. 52: 524

16. Hamilton, J. W., F. W. Spierto, R. R. MacGregor, and D. V. Cohn. 1971. Studies on the biosynthesis in vitro of parathyroid hormone. II. The effect of calcium and magnesium on synthesis of parathyroid hormone isolated from bovine parathyroid tissue and incubation medium. J. Biol. Chem. 246: 3224.

17. Brewer, Jr., H. B., T. Fairwell, R. Ronan, G. W. Sizemore, and C. D. Arnaud. 1972. Human parathyroid hormone: amino-acid sequence of the amino-terminal residues 1-34. Proc. Natl. Acad. Sci. U. S. A. 69: 3585 .

18. Jacobs, J. W., R. T. Sauer, H. D. Niall, H. T. Keutmann, J. L. H. O'Riordan, G. D. Aurbach, and J. T. Potts, Jr. 1973. High sensitivity N-terminal sequence analysis of human parathyroid hormone. Fed. Proc. 32: 648. (Abstr.) 